\title{
How to Trace the Works of Masters
}

\author{
Xiaojie Zhang \\ Painting Teaching and Research Office \\ New Media Arts Department \\ Academy of Chinese Traditional Opera \\ Beijing, China
}

\begin{abstract}
Tracing is a very common word in art field. In the foreign history of art, tracing is a main method and means to learn painting techniques, use and inherit excellent tradition for reference. The simple copying can not be called tracing. First, a copier shall know learning needs, select appropriate excellent works and carry on a research study. At present, our major task in art education is to set tracing program and collect excellent painting works, which is a long-term career to improve the art level of our country, help later generations and prosper art creation.
\end{abstract}

\section{Keywords—tracing; sketch; oil painting; art education}

\section{INTRODUCTION}

People usually gain experiences from life and books. It is the same that we can learn others' good methods and virtues from books in the study of tracing. Tracing is a common work in art field. Copy means to write or paint according to the original work. Trace means to write or paint on a thin transparent paper covering an original work. In the foreign history of art, tracing is always a main method and means to learn painting techniques, use and inherit excellent tradition for reference.

Take the learning of sketch as example. Leonardo da Vinci, one of three outstanding heroes in the Italian Renaissance, first proposed to divide the systematic learning of sketch into three stages, tracing, sketching of plaster and sketching of figure model. At the beginning of the establishment of art education of higher institutions in the ancient Western, tracing works of mater was treated as basic content in art course. A college should possess a huge number of excellent painting works. Students were encouraged to go to art museum regularly. The tracing is divided into three stages according to grades of students from difficult to easy. The first is basic tracing; practice to trace still life and the five sense organs. The second is tracing of part of figure. The third is tracing and sketching of a complete figure. Thus it can be seen that it has a very good effect to learn excellent works of predecessors to improve students. Currently, tracing is a weak link in the fine arts study of Chinese colleges of fine arts, which also relates the difficulty for students to see authentic paintings. In recent years, the domestic and foreign exchange exhibition environment is getting better and better. A lot of world famous works are introduced into our country for exhibition. The gradual establishment of collection mechanism of our museums and art museum will provide more opportunities for students to study. The world famous Russian Repin Academy of Fine Arts has always been followed this learning tradition. However, it is not always for students to trace original works of masters in museum at any time. It needs complicated procedures and strict identity constraints. Only students in junior period or above are allowed to get permit from college uniformly in summer art practice period to go to museum. Therefore, it is a good learning method to trace picture album and printing products. By tracing original works or picture of works in good printing quality, we could know the virtue of original works and detail processing techniques. In the practice of sketching, students often don't know how to sketch in detail and how to make a relatively complete picture. By tracing excellent works, students could accumulate experience gradually and lay a good modeling foundation for future program. Tracing is not a kind of simple copying. From the need of study, students could select excellent works and carry on a research study.

\section{TRACING OF SKETCH}

Before tracing, first is to study the materials and tools. The technique of expression could not be achieved without knowing the use of materials and tools and the painting procedures, and say nothing of learning tracing. Different to the simple drawing materials of our artists, the materials that ancient Western masters would like to use include dry material and wet material. Dry materials are charcoal pencil, pastels, color pencils and natural mineral colors. Wet materials generally are watercolors, colored inks, watersoluble toner and etc. It would be better to select materials with similar texture in tracing. The main steps for sketching and tracing: mount sketch paper and make grounding according to the original work; avoid spending a lot of time in painting halftone and background colors. Artists often accent or whiten picture to order to form a sketching relationships with rich changes and highlight subject image, so they seldom select bright color as grounding. Generally, add water to adjust watercolor or gouache and then add a few drops of latex to prevent bleaching; apply background colors with soft brushes or sponge rollers uniformly and air. In addition, use overnight tea or sugar-free coffee as grounding to achieve a yellowish antiquing effect. In tracing, use sulfuric acid paper for rubbing painting. Use dash line to draw contour of painting subject, shadow line and obvious structure line. Use charcoal pencil or brown pastel to paint the back of sulfuric acid paper fully. Gently put the sulfuric acid paper on the painting board mounted with paper to 
prevent movement. Put the original work beside and meticulously trace from the whole to details and from the shallower to the deeper. The tracing of head portraits is the main content in the tracing course the freshmen of the Repin Academy of Fine Arts, because the content of their coloring course is also about head portrait. It is required to draw paint with same size of original work and painting tools. Teachers strictly control tracing steps and methods in order to supervise student's work in same form and expression with the original work. By tracing excellent works, students could learn expression methods of painting. Students could know how to make a structure, balance hue of picture, handle the relationship of light and shade, express texture and etc. It is same to trace a plaster or human body. Use different techniques with different materials. The figure in many of Lenardo da Vinci's portrait sketch works is shaped with brown pencil in diagonal. The whole picture goes from light to dark. The characters in the painting are also used with line of same direction that are soft and dedicate. The highlights of some works also are processed of whitening process with whiting. Rembrandt painted a lot of sketches with squid ink and even Chinese ink. He controlled the change of shade through water. Pastels are common tools many world famous masters use, because they are soft, fast and with varied changes in shade, with characteristics of water color after adding with water. I traced a figure work of Cischakov. The original work is painted with Italian pencil, which shows the brightness and delicateness of charcoal pencil. It is difficult to see its brushwork. I selected pencil and Dark Narcysus (a soft pastels) for my painting. In order to blend pencil and Dark Narcysus, I first used Dark Narcysus and stomp to paint the relationship of light and shade whose characteristics are in dark color, fast, easy to modify. But it is difficult to process details. Later use pencil to paint in detail without using Dark Narcysus. Use pencil style of drawing to paint layer by layer. The first layer of Dark Narcysus shade is almost covered. Due to characteristics of Dark Narcysus, I finished my work of human body, as shown in Fig.1, in a short period.

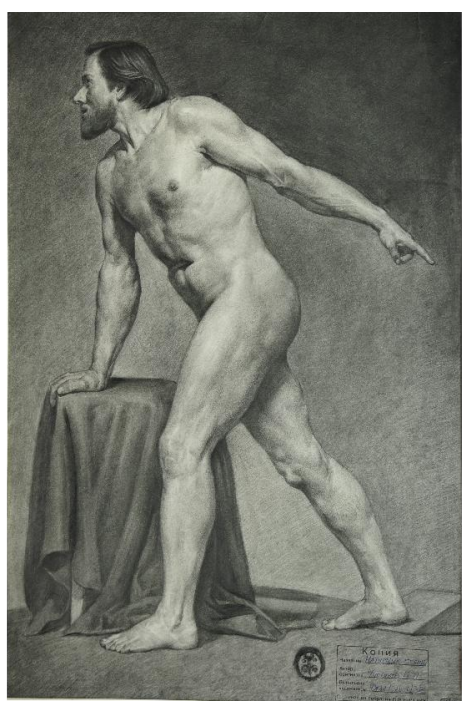

Fig. 1 Tracing of Figure Sketch

\section{TRACING OF OIL PAINTING}

The tracing of oil painting of ancient masters is slightly complicated compared with sketch. Generally, early Western oil painters like applying ochre or brown color as grounding on canvas; individual artists, such as Rue Rubens, like applying gray background. The main role of intermediate color could link all colors, or else it will be too cool or monotonous. This colored base is often used for transparent stained method (described later). The application of this method could produce a gray vision, more attractive than directly painting gray.

Here is a simplified method suitable for the tracing of oil painting before impressionism - from the Renaissance to Baroque period (artists in different times and regions use different methods; we do not discuss it here). This period is the flourishing period of classic oil painting. Its characteristic is emphasizing sketch factors and the color relationship is relatively simple. Generally, draw the relationship of sketch first and then the relationship of colors. This painting method separating form and color is called indirect painting method. Take my tracing of Rembrandt "Old Man's Portrait" as example. Select a rough canvas according to the oil painting to be traced. Stretch the $100 \mathrm{~cm} \times 80 \mathrm{~cm}$ canvas tight and apply latex twice. Fine arts students of Repin Academy apply the mixture of water and soaked gelatin in scale of $1: 1$ on canvas. We generally use white latex. After drying, grind the surface with fine sandpaper gently. The bottom material (sold in market) is needed to applied in three times. Make sure apply latex when the last layer of latex is dry.

The canvas with colored base can be applied with acrylic color and watercolor to replace mineral color that ancient artists used. Blend them in when you apply the last layer of bottom material, as shown in Fig. 2. In ancient times, artists control the drying rate according to their needs. Some artists even added oily materials into base. The More oil painter applies the slower the drying rate is. The method of rubbing painting is similar with that of sketch. It should be specially pointed out that we can print a black and white painting if the works is in a large size. We can use the printing painting for rubbing. Use light ink to draw outline; Refer to the white and black draft and draw the sketch relationships with white and black color according to the original work. In drawing sketch relationships, it is required to draw all details and texture, in line with the original work. The color of finished painting is slightly light than that of the original one. When it is dried, continue the next step, as shown in Fig. 3.
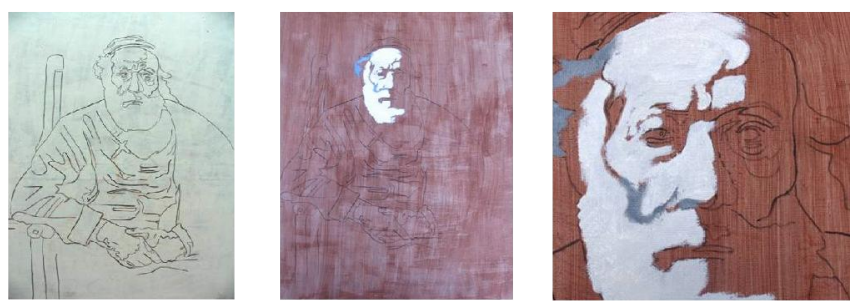

Fig. 2 Tracing of Rembrandt's “Old Man's Portrait” - with colored base 

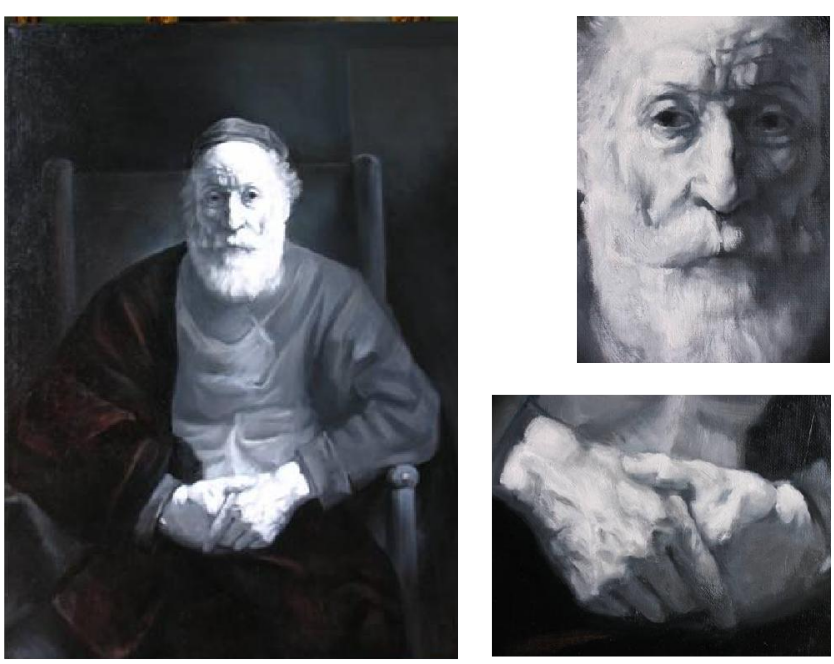

Fig. 3 Tracing of Rembrandt's Old Man's Portrait - sketch details

According the hue of the original work, select yellowish brown, reddish brown, ochre, burnt umber and other soil colors as well as bright red, emerald green, cobalt blue and other high-purity colors of good transparency. Use Mattie resin as transparent color paste (it is available in market, or it can be replaced by megilp; but its effect is not as good) to mix color. It would be better to use soft brushes. Turpentine can be used as diluent. By staining picture in part with this color, you may be surprised to find that the color of picture is like flowing colored transparent glass, full of luster. The black, white and gray of sketch are revealed under other colors, creating a special gray color, especially in the transition of bright gray on face and blue veins on hand. It would be transparent and vivid, which couldn't be realized by the direct painting method. Use less opaque color to take advantage of the brightness of color and achieve the effect of original work. Stain the painting for a few times and achieve the saturation effect. Repeat it when it is dry. When the painting is nearly dry, stains the whole picture with extremely light ochre and burnt umber mixing with transparent color paste. Use opaque color for few details. Fig. 4 is the completed work.

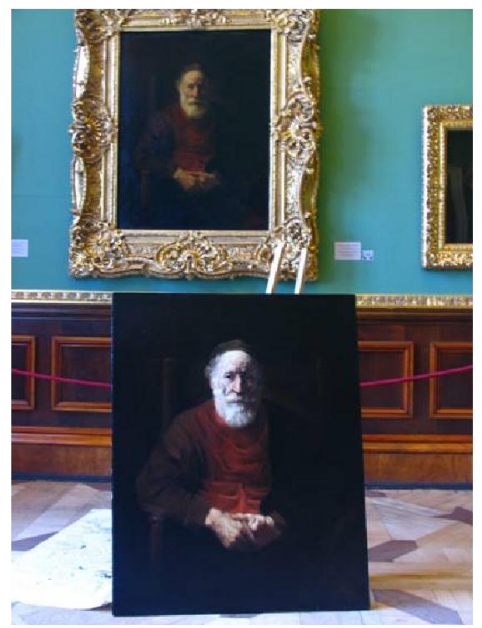

Fig. 4 Tracing of Rembrandt "Old Man's Portrait" - Completed Work
Comparing to indirect painting method, the direct painting method, which is commonly used by most painters, makes shapes and colors act on the picture at the same time. Colors and sketch are contained in every painting of the painter. Tracing such works through draft likes we draw at ordinary times, we can directly apply colors according to the original works, or use colored base.

Steps are important in tracing an oil painting. Oil painting needs time to dry, so we should analyze how to trace first, sometimes the order of steps will influence final effect of the tracing, so we should trace the whole painting first, and then the parts, finally the details( or according to Outline making texture of the draft first). When we trace a painting, we should follow it totally and know all painting skills. Color of this part is light or dark, how to connect, how to turn, cold or warm, thin or thick of the texture, how to deal with the demeanor of the figure, how to unify the expressions of the five sense organs with demeanor? Only after repeated deliberation can we learn something.

\section{IMPORTANCE OF TRACING}

Tracing course has been canceled in many departments of arts in China at present, only a few of parts treat this course as assignments, and students don't value tracing. The effect of tracing is obviously good. It is a process to appreciate and further study of painters or schools of certain ages. Tracing is much deeper than appreciation, because it makes every details deeply imprinted in the minds of students, turns what they learn into their own knowledge, and digests them during painting from nature, so that to make foundations for future stylized art practice. They find formal rules of arts from primary tracing and then use the rules to painting. By tracing they can learn painting tools comprehensively from rigorous and scientific attitude towards learning and experience of foreigners; they can use skills properly and form their own art characters. Tracing also should choose objectives purposefully, totally understand what problems they should solve and choose works pointedly, they can get twofold results with half the effort. In some art colleges with no painting profession, students' comprehensive ability of painting is relatively weak, so guide is more important than development. In basic modeling training, if the student can trace scientifically, they can improve the level of painting constantly, obtain learning directly from the original works, greatly saving time spent on learning of art, changing students from passive to accept the teacher hand rival training way into choose the required knowledge and skills from tracing original works. At present, our major task in art education is to set tracing program and collect excellent painting works, which is a long-term career to improve the art level of our country, help later generations and prosper art creation.

\section{REFERENCES}

[1] Xing Li. Self-consciousness and Specification - European Academy of Fine Arts from 16 Century to 19 Century. China Renmin University Press. 
[2] Max Doerner. Painting Techniques and Materials of European Painting Masters. Chongqing Publishing House.

[3] Liu Komgxi. Find the Original Source, Use Ancient Methods Today An Analysis and Teaching Thought on European Classical Painting Techniques. Academy of Fine Arts of Capital Normal University Publishing House. 